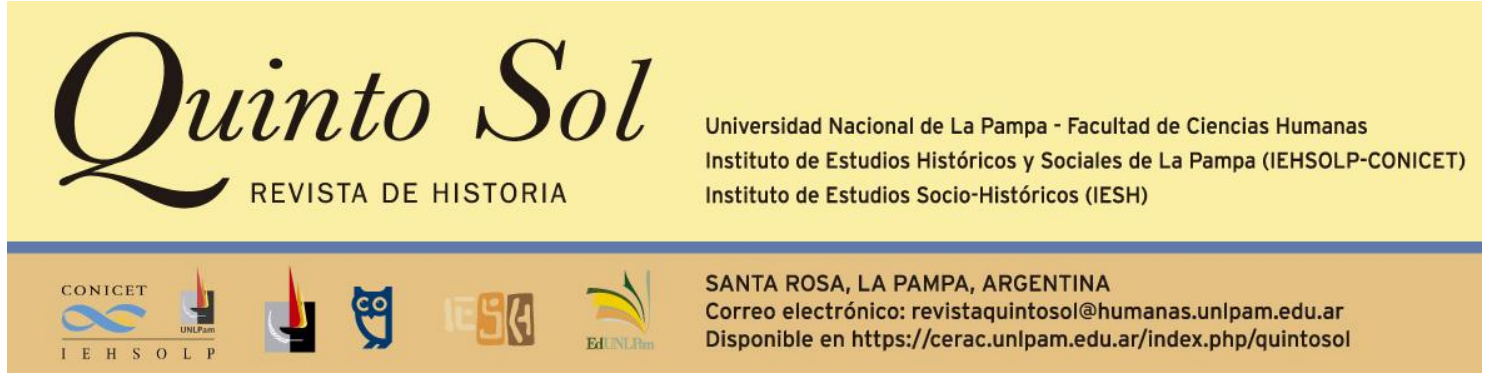

Quinto Sol, vol. 24, n 1, enero-abril 2020, ISSN 1851-2879, pp. 1-4

DOI: http://dx.doi.org/10.19137/qs.v24i1.4255

Esta obra se publica bajo licencia Creative Commons 4.0 Internacional. (Atribución-No ComercialCompartir Igual)

\title{
Marisa Moroni, Fernando Casullo y Gabriel Carrizo (Eds.) Justicia, seguridad y castigo. Concepciones y prácticas cotidianas en Patagonia (1884-1955). Rosario: Prohistoria/EdUNLPam, 2018, 256 páginas.
}

\section{Melina Yangilevich}

Consejo Nacional de Investigaciones Científicas y Técnicas

Universidad Nacional del Centro de la Provincia de Buenos Aires. Instituto de Estudios Histórico-Sociales "Prof. Juan Carlos Grosso". Instituto de Geografía, Historia y Ciencias Sociales.

Argentina

Correo electrónico: myangilevich@gmail.com

El libro editado por Marisa Moroni, Fernando Casullo y Gabriel Carrizo constituye un aporte valioso por un conjunto de razones que esperamos poder reflejar en estas páginas. En primer término, se trata de un estudio de imprescindible lectura para quienes se interesen por los tópicos analizados: justicia, instituciones de seguridad y castigo, enmarcados entre fines del siglo XIX y la primera mitad del siglo XX. La obra indaga en profundidad los modos diversos y contradictorios en los que el Estado central y luego, los Estados provinciales -en un recorrido inverso que el de buena parte del territorio que formó la República Argentina-, se establecieron y funcionaron en el espacio patagónico. En este sentido, no puede menos que coincidirse con Osvaldo Barreneche, a cargo del prólogo de la obra, cuando sostiene que el libro implica una "oxigenación" en la historiografía local.

El texto abreva en diferentes líneas de análisis y enfoques que aportaron a la elaboración de contribuciones densas para pensar los diversos objetos de 
investigación. Una de estas líneas es la que proviene de los estudios históricos a partir de una perspectiva regional. Esta resulta relevante en el marco de los estudios patagónicos por la prolífica producción resultante, que contribuyó a poner en cuestión cierto consenso historiográfico sobre el carácter centralizante de los procesos históricos, donde los casos territorianos y provinciales no constituyeron casos "atrasados" respecto de otros "modernos", sino que deben estudiarse desde su propia especificidad. Una segunda perspectiva -que no está disociada de la anterior-, es la que aborda la conformación del Estado considerando su "rostro humano" o "desde adentro", lo que implicó analizar agencias, figuras y prácticas sociales antes que estructuras consolidadas, difíciles de encontrar en buena parte del territorio argentino.

El libro, como se señaló, inicia con un prólogo de Barreneche cuyos aportes al campo no necesitan ser señalados en estas páginas. Lejos de realizar una presentación de los diversos textos para la ocasión, elaboró una contribución significativa ya que se dedicó a señalar los diálogos que pueden establecerse entre los diversos capítulos y las producciones de los últimos años sobre las temáticas vinculadas a la administración de justicia, el castigo y las instituciones de vigilancia. El recorrido realizado es amplio, no solo en el marco temporal -de la policía parisina durante el siglo XVIII a los procesos judiciales durante la postguerra-, también lo es en el contexto espacial. Los textos seleccionados reflejan diferentes espacios de América, Europa y Asia. Esta reflexión diacrónica y sincrónica coloca al libro en relación a esta producción, tan vasta como fructífera.

Este prólogo se articula con el resto del contenido que le sigue: una introducción y diez capítulos que recorren diferentes aspectos sobre las agencias, instituciones y prácticas vinculadas a la cuestión criminal en el espacio patagónico. Los apartados se agrupan de acuerdo a la temática central que ocupa a cada uno de ellos. La primera parte está abocada a analizar diferentes aspectos vinculados a la administración de justicia, la segunda a la policía y la tercera a los espacios de encierro.

En la introducción, Moroni, Casullo y Carrizo -especialistas y con una vasta trayectoria en las temáticas examinadas en la obra- señalan que los trabajos incluidos "recogen los aportes empíricos sobre la intervención de diferentes instituciones y agentes" en el marco del proceso de formación y consolidación estatal (p. 23). Más allá de esta afirmación, sin duda, los capítulos se sostienen en sólidos postulados teóricos, no obstante, en algunos casos la apelación a marcos conceptuales es más explícita que en otros. Tal el caso de los textos de Casullo, Pilar Pérez, Pablo Navas y Valeria Flores. La primera parte del texto versa sobre la administración de justicia letrada y su relación con diferentes sectores. El escrito de Casullo reconstruye la conformación de una cultura letrada en una sociedad civil novel y el funcionamiento de la administración de justicia, alejado del postulado ideal y más próximo a la experiencia de los actores a partir de un extenso conflicto entre un periódico y un juez letrado del territorio de Río Negro. Mientras que Gabriel Rafart adopta un enfoque similar sobre la justicia del territorio de Neuquén para indagar en la litigiosidad laboral y las intervenciones en favor de los trabajadores aun cuando no existía un fuero específico. Este proceso procuró consolidarse a partir de la ampliación de las estructuras judiciales existentes, de mayores recursos y del nombramiento de letrados afines a la doctrina peronista, aunque se vio matizado por la rotación de los agentes judiciales que impidió la estabilidad en el desempeño de tales cargos. Por su parte, Moroni indaga en otro aspecto de la cultura judicial de los actores a partir de la utilización de la denuncia por 
desacato durante la primera mitad de la década de 1950. Lejos de postular la existencia de una conducción partidaria verticalista, su estudio muestra la utilización de la denuncia para forzar la resolución de conflictos familiares o como vía para asegurar la fidelidad política de los denunciantes a los principios del peronismo. El último texto de esta parte es el de Hernán Bacha, quien estudia la conformación institucional del Poder Judicial, así como las transformaciones ocurridas luego del peronismo. El autor concluye que las bases institucionales sobre las que se estableció la justicia con la creación provincial fueron las existentes en el período territoriano. Desde 1960, los cambios en este poder se sucedieron a partir de una nueva constitución provincial y de la creación de organismos incluidos en el Código Procesal Penal.

El apartado dedicado a la policía se inicia con el estudio de Pérez, allí se analiza la experiencia de "hacer la policía" en los territorios nacionales de Río Negro y Chubut entre 1884 y 1950. Dichas prácticas implicaban múltiples tareas: recorrer, vigilar y relevar el territorio, garantizar la propiedad privada y apresar a indígenas no reducidos. Este proceso concertó la confluencia de diferentes fuerzas: ejército, policía y gendarmería. Uno de los rasgos salientes de sus integrantes fue la escasez de personal formado, las dificultades para el cobro de los sueldos y las grandes distancias a recorrer. El texto de Pérez dialoga con el de Melisa Fernández Marrón, quien se enfoca en las prácticas cotidianas de la policía del territorio de La Pampa en un contexto de precariedad material -nada sorprendente- que articulaba aquello que se esperaba de esta institución, las demandas de la sociedad y lo que los agentes entendían debían realizar. Tal combinación generó un saber hacer experimental por parte de los agentes insertos en el contexto en el que vivían y atentos a las sensibilidades de la comunidad. El texto de Carrizo, que cierra este apartado, se enfoca en los trabajadores que estuvieron bajo el control de la Gobernación Militar de Comodoro Rivadavia durante el peronismo, a partir de una interna sindical generada en una huelga de 1947. El contexto estaba condicionado por el temor extendido al "fantasma" del comunismo y donde cualquier connato de organización obrera era considerada una amenaza. El autor reconstruye los modos de implementación del control, la vigilancia y la represión en esa gobernación.

En la última parte se analiza otra de las agencias estatales que se estableció en la Patagonia a partir de fines del siglo XIX: la cárcel. El trabajo de Milagros Pierini se centra en la organización de una escuela en la cárcel de Río Gallegos en el período territoriano, donde los objetivos de moralización y resocialización descansaban sobre los beneficios de la educación. Estos se vieron limitados por las restricciones presupuestarias, la precariedad de las instalaciones y la escasa formación del personal. De tal manera, la educación carcelaria no escapó a las condiciones específicas de la misma institución de encierro. Por su parte, la investigación de Navas también se enfoca en el establecimiento carcelario de Río Gallegos para reflexionar sobre las políticas de control social aplicadas en el territorio nacional de Santa Cruz, focalizando en dos momentos considerados como clivajes. Según el autor, en el primero (18851920), se inició el establecimiento de las primeras instituciones con una marcada distancia entre la agenda gubernamental y su factibilidad. Mientras que, en el segundo, caracterizado como "normalización" (comenzó en 1930) el Estado nacional mostró mayor vocación por instrumentar políticas de control social en la frontera, así como regular las instituciones carcelarias. El último texto que cierra este apartado es el de Flores, quien indaga en la conformación de un sistema carcelario en el Territorio 
Nacional de la Pampa entre 1884 y 1930. El análisis es relevante en la medida que se enfoca en establecimientos alejados de los grandes centros urbanos y que recibieron escasa atención de la literatura especializada. Los resultados no arrojan diferencias respecto de aquellos sobre otros espacios de encierro en tanto compartían problemas de infraestructura, escasez de ropa, uniformes, ausencia de espacios para internos y guardiacárceles, deficiencias sanitarias, epidemias y enfermedades. A las carencias materiales se sumaban las normativas. La autora, en coincidencia con Navas, afirma que esta situación comenzó a revertirse hacia 1930 con un mejoramiento en la organización de las instituciones y la unificación de la legislación.

Como se señaló, la obra resulta una contribución relevante para comprender los modos -complejos y contradictorios- en los que se conformó y afianzó el Estado en Patagonia a partir de la coexistencia de diferentes agencias. Estas estaban sostenidas sobre los hombros de pocas personas, sobrecargadas de tareas, escasamente formadas, con falta de edificaciones apropiadas y en un espacio por demás extenso que acentuaba las carencias existentes. Ello implicó que la consolidación de la presencia estatal fuera el producto de una negociación cotidiana entre los agentes que decían actuar y hablar en nombre del Estado y los vecinos de las comunidades, que en ocasiones debían asumir las funciones que aquel no podía realizar. En este contexto, el uso de la violencia era una herramienta de construcción de la autoridad, siempre en disputa. Como señala Pérez (p. 144), no tanto por aquellos sobre los que se ejercía esa violencia, sino por las agencias existentes y las diversas fuerzas de seguridad. El itinerario sinuoso recorrido por las agencias estatales no fue equivalente al de una ausencia deliberada, lejos de ello contribuyó a la producción de un espacio social. Los argumentos sostenidos hasta aquí inducen a pensar que el libro es relevante en la historiografía especializada y de necesaria consulta para quienes se interesen en esta problemática. 